\title{
Knowledge, attitudes, and beliefs about acute coronary syndrome among patients with type 2 diabetes*
}

\author{
Camille Alardis Hunte Johnson ${ }^{1}$ \\ (D) https://orcid.org/0000-0002-0399-9249 \\ Natássia Condilo Pitta ${ }^{2}$ \\ (D) https://orcid.org/0000-0003-0098-3310 \\ Carina Aparecida Marosti Dessotte ${ }^{2}$ \\ (1) https://orcid.org/0000-0002-5521-8416 \\ Rosana Aparecida Spadoti Dantas 2 \\ (D) https://orcid.org/0000-0002-3050-7000 \\ Lídia Aparecida Rossi² \\ (D) https://orcid.org/0000-0002-4141-861X
}

Paper extracted from master's thesis "Knowledge, attitudes, beliefs and responses of type 2 diabetes clients toward acute coronary syndrome", presented to Universidade de São Paulo, Escola de Enfermagem de Ribeirão Preto, PAHO/WHO Collaborating Centre for Nursing Research Development, Ribeirão Preto, SP, Brazil. This study was financed in part by the Coordenação de Aperfeiçoamento de Pessoal de Nível Superior (CAPES) - Finance Code 001, Brazil and by Ministry of Finance of Guyana (No. 243124.888- 78), Guyana.

${ }^{1}$ Charles Roza School of Nursing, Linden, Guyana.

2 Universidade de São Paulo, Escola de Enfermagem de Ribeirão Preto, PAHO/WHO Collaborating Centre for Nursing Research Development, Ribeirão Preto, SP, Brazil.

\begin{abstract}
Objective: to evaluate the knowledge, attitudes, and beliefs of Guyanese individuals with type 2 diabetes regarding acute coronary syndrome and explore associations between these measures and the population's sociodemographic and clinical characteristics. Method: cross-sectional study conducted in Linden, Guyana, with sixty type 2 diabetics, interviewed using a sociodemographic and clinical questionnaire and the Acute Coronary Syndrome-Response Index. The MannWhitney test was used to assess potential differences between groups according to the ACS-Response Index subscales, and sex, age, time since diabetes diagnosis, and body mass index and the Kruskal-Wallis test to compare the ACS-Response Index subscales according to educational level. Results: only two participants correctly answered more than $70 \%$ of the Knowledge subscale. Participants obtained low mean scores in all subscales. Less than half of the participants reported chest pain and arm pain as symptoms of heart attack. Significant differences were found when comparing Knowledge $(p=0.008)$ and Attitudes $(p=0.009)$ according to educational level. Conclusion: individuals with type 2 diabetes showed low level of Knowledge, Attitudes, and Beliefs. Participants who scored the highest in Knowledge and Attitudes presented the highest educational level. The results show a need for health professionals to heed knowledge deficits regarding acute coronary syndrome among type 2 diabetes.
\end{abstract}

Descriptors: Knowledge; Diabetes; Acute Coronary Syndrome; Attitudes; Beliefs; Nursing.

\section{How to cite this article}

Johnson CAH, Pitta NC, Dessotte CAM, Dantas RAS, Rossi LA. Knowledge, attitudes, and beliefs about acute coronary syndrome among patients with type 2 diabetes. Rev. Latino-Am. Enfermagem. 2021;29:e3503. [Access Available in: DOI: http://dx.doi.org/10.1590/1518-8345.5435.3503 


\section{Introduction}

Non-communicable diseases, such as cardiovascular diseases, cancer, diabetes, and chronic respiratory diseases, are the leading cause of death and disability worldwide ${ }^{(1)}$. Diabetes, for example, is a high-risk factor for cardiovascular diseases(2). In 2017, the estimated prevalence of diabetes among individuals aged 18 to 99 was 451 million worldwide, projected to be 693 million by $2045^{(3)}$. Moreover, lower and middle-income countries have the most significant health burden of non-communicable diseases, as over three-quarters of deaths from these conditions occur in these countries ${ }^{(4)}$.

In 2016, cardiovascular diseases were the leading cause of death in Guyana, accounting for $34 \%$ of deaths among 30 to 69 year-old-individuals ${ }^{(5)}$. In addition, a recent study ${ }^{(6)}$ addressing the national diabetes prevalence in the country found a rate of $18.1 \%$ among adults, with a higher prevalence in women $(21.4 \%)$ than men $(15.1 \%)$.

Due to a lack of knowledge, diabetic individuals often fail to engage in self-care activities to control and prevent cardiovascular diseases, such as coronary artery disease. Additionally, acute coronary syndrome (ACS) is frequently asymptomatic in diabetic patients, leading to a delay in seeking assistance ${ }^{(7)}$ and contributing to inappropriate self-care behaviors. Low levels of knowledge and inability to interpret and respond appropriately to ACS symptoms are problems faced globally(8).

The knowledge, attitudes, and beliefs of individuals diagnosed with ischemic heart disease are associated with delays in seeking help ${ }^{(9)}$. Proper knowledge may motivate people to take care of their health ${ }^{(10)}$ and inspire them to respond appropriately in case of a heart attack(11). However, knowledge about ACS and its symptoms is insufficient to persuade a person to seek the needed early treatment ${ }^{(12-13)}$. Therefore, it is important to consider the psychosocial factors involved, such as personal beliefs, values, and emotions ${ }^{(12)}$, and the context where people live.

Guyana is currently facing a challenge in its healthcare system, which places little emphasis on preventing ACS among patients with diabetes. The education of patients with type 2 diabetes is mainly focused on preventing complications, such as peripheral vascular disease, hypertension, and stroke. Furthermore, there is no evidence of the level of knowledge among people with diabetes on acute coronary syndrome; individuals with diabetes are at high risk for this condition. Such knowledge can offer a basis for educational interventions suitable for this population to improve self-efficacy in the self-management of cardiovascular complications, which are among the most common causes of mortality among Guyanese citizens ${ }^{(4)}$. Thus, it is essential to assess the knowledge and beliefs of patients with type 2 diabetes on ACS and their attitudes when responding to its symptoms.

The knowledge, attitudes, and beliefs of type 2 diabetic patients toward ACS were assessed in this study using the Acute Coronary Syndrome Response Index (ACS-Response Index). The ACS-Response Index was developed, based on Leventhal's Self-regulatory Model of Illness Behavior ${ }^{(9)}$, to assess cognitive and emotional aspects related to the patients' response in the face of a heart attack. However, Leventhal's Common-Sense Model of Self-regulation explains the management of chronic conditions in everyday life ${ }^{(14)}$. According to this Model, a patient's behaviors and feelings about the disease's symptoms are based on physical experiences. These experiences allow patients to identify symptoms and form their beliefs about them. Thus, the patients' perspectives about the illness and its treatment are constructed ${ }^{(14)}$. This index was developed and validated to assess patients' knowledge, attitudes, and beliefs toward coronary heart disease and their response to its symptoms ${ }^{(9)}$. From this perspective, responses to a health threat such as ACS are associated with a patient's ability to perceive and locate symptoms, revealing one's relationship with the disease. Thus, knowledge, attitudes, and beliefs influence a patient's perceptions about the $\operatorname{ACS}^{(9)}$.

Previous studies have addressed the knowledge, attitudes, beliefs, and perceived risks of ACS and its symptoms among patients diagnosed with ischemic heart disease ${ }^{(8,13,15-17)}$. However, no studies addressing the knowledge, attitudes, and beliefs regarding ACS among type 2 diabetic patients were found, which is the focus of this study. Recently, researchers performed a scoping review to analyze 16 articles addressing the knowledge and perceptions of patients with type 2 diabetes towards cardiovascular disease prevention, reporting that patients with type 2 diabetes could not identify the factors associated with cardiovascular disease. As a result, they had a knowledge deficit related to the disease at the time of diagnosis, failing to recognize cardiovascular risk factors and manage them. In addition, knowledge and perceptions were associated with the patients' demographic characteristics such as years of instruction, race, age, and region of residence ${ }^{(18)}$.

Deficits in knowledge, lack of financial and social support, in addition to beliefs and attitudes, were identified as factors influencing self-care among Chinese individuals with acute coronary syndrome and diabetes ${ }^{(19)}$. The ACSResponse Index was used to assess knowledge, attitudes, and beliefs toward the ACS symptoms among 50 Lebanese patients after a myocardial infarct: 12 (24\%) of whom had diabetes ${ }^{(15)}$. The author found a lack of knowledge concerning heart attack symptoms and inconsistent beliefs about the need to seek help in the event of a heart attack 
and perceptions concerning their ability to control their disease ${ }^{(15)}$.

No studies were found on the knowledge, attitudes, and beliefs of Guyanese patients with type 2 diabetes about ACS symptoms. Identifying the perceptions of this group toward ACS symptoms is paramount and contributes to planning and improving educational programs focused on the ability of patients to recognize symptoms and respond to a heart attack appropriately and timely. Therefore, this study aims to evaluate the knowledge, attitudes, and beliefs of Guyanese individuals with type 2 diabetes about acute coronary syndrome and explore associations between these measures and this population's sociodemographic and clinical characteristics.

\section{Method}

\section{Study design and participants}

This is a cross-sectional study, reported according to the Strengthening the Reporting of Observational Studies in Epidemiology (STROBE) statement. Data were collected from June 2019 to January 2020, at the Linden Hospital Complex, in Region 10, Guyana. The Linden Hospital Complex includes three hospitals (two district hospitals and one regional hospital). The study participants were selected from the Mackenzie Hospital (the regional hospital) and the Upper Demerara Regional Hospital (one of the district hospitals). The Mackenzie Hospital has 115 beds and provides general medicine, general surgeries, obstetrical and gynecologist, pediatric, and neonatal care, while the Upper Demerara Regional Hospital provides outpatient services, such as antenatal, chronic disease, and family health clinics. The availability of resources constrained the period of data collection. The participants were selected by consecutive and nonprobabilistic sampling identified through the hospital database by consulting hospitalization charts and followup visit schedules at the outpatient clinic.

Inclusion criteria were adult patients with type 2 diabetes, regardless of sex, with cognitive competence to answer the questionnaire. Participants were considered cognitively competent if they answered questions concerning their current home address, current date, and time. Additionally, patients diagnosed 36 months ago or later were included. The reason is that metabolic abnormality atherogenic dyslipidemia occurs before diabetes is clinically diagnosed; thus, early education regarding ACS is vital for these patients( ${ }^{(20)}$. Exclusion criteria were persons residing in difficult-to-access communities without public transportation and individuals not attending the follow-up during the data collection period.

\section{Measures}

Sociodemographic and Clinical data Questionnaire

A questionnaire was developed to collect sociodemographic and clinical data, including date of the interview, date of birth, sex, marital status, level of education [primary, secondary, trade (postsecondary) and university level], time since the diabetes diagnosis, weight and height, physical activities (walking, running and riding - bike), and comorbidities.

\section{Acute Coronary Syndrome Response Index (ACS-Response Index)}

The ACS-Response Index was developed to assess the knowledge, attitudes, and beliefs concerning ACS symptoms and responses to symptoms ${ }^{(9)}$. It consists of 33 questions divided into three subscales, which measure Knowledge, Attitudes, and Beliefs. With 21 dichotomous items, the subscale Knowledge addresses various symptoms related to ACS (15 questions) and unrelated to ACS (six questions reverse code). One point is assigned to each correct answer and zero points to each incorrect answer. This subscale's total score is obtained by adding correct answers, ranging from 0 to 21 . The subscale Attitudes contains five items (22 to 26), and the subscale Beliefs contains seven items (27 to 33). These subscales include questions about seeking help in an emergency and the respondents' perceptions regarding self-confidence in recognizing symptoms. These two subscales include a four-point ordinal scale, ranging from one to four. The Attitudes subscale includes the following possible answers: not at all=1, little sure $=2$, pretty sure $=3$, and very sure $=4$. The possible answers for the Beliefs subscale are strongly agree $=1$, agree $=2$, disagree $=3$, and strongly disagree $=4$. The Beliefs subscale has three reverse coded items $(27,31$, and 33$)$. The total score ranges from 5 to 20 for the Attitudes subscale and 7 to 28 for the Beliefs subscale. Higher scores in any of the subscales reflect more positive responses to the ACS symptoms. This instrument should be used as an index rather than a scale. Therefore, as an index that assesses observed facts, the objective is to compare the scores of each subscale (Knowledge, Attitudes, and Beliefs) separately as concepts that influence responses regarding $\mathrm{ACS}^{(9)}$.

Dr. Barbara Riegel authorized the use of the ACSResponse Index. The internal consistency obtained in the validation study of the original English version was 0.82 for the Knowledge subscale and 0.76 for both the Attitudes and Beliefs subscales ${ }^{(9)}$. English is the primary language spoken in Guyana; however, considering cultural differences between the population in which the instrument was tested and the population addressed in this study, the ACS-Response Index was tested on ten patients from three health facilities to ensure the instrument's content and 
face validity. These ten patients were selected according to the same inclusion and exclusion criteria previously mentioned. All the patients answered the items without making any queries, and there was no need to adjust the instrument. Therefore, these ten participants were not included in the final sample. The instrument's reliability was also tested in this study's final sample. The internal consistency of the Knowledge subscale assessed by the Kuder-Richardson-20 coefficient (KR-20) was 0.962, given this subscale's dichotomous answer format. Cronbach alpha coefficients obtained for the Attitudes and Beliefs subscales were 0.830 and 0.798 , respectively. Values equal to or higher than 0.65 for the KR-20 and 0.70 for the Cronbach's alpha were considered acceptable ${ }^{(21)}$.

\section{Data collection}

The first author selected potential participants from the medical records in the Mackenzie Hospital and the Upper Demerara Regional Hospital. The potential participants were contacted via telephone and at the medical clinics. Eight out of 84 eligible patients no longer resided at the addresses found on their charts; six did not respond to the invitation to participate in the study; five refused to participate; two emigrated to other countries, and three worked outside Linden. Thus, the sample consisted of 60 participants. The hospital database was accessed manually to collect the patients' sociodemographic and clinical data. Data not available in the medical records were collected through interviews. Data collection was conducted by the first author through face-to-face interviews, according to the availability of participants and in the places indicated by them.

\section{Data analysis}

Data were processed and analyzed using IBM SPSS Statistics for Windows, Version 24.0 (Armonk, NY: IBM Corp.), and descriptive analyses were performed for all the variables.

The Mann-Whitney test was performed to assess potential differences between groups according to the scores obtained in the ACS-Response Index subscales and sex (male versus female), age (younger than 60 years old versus 60 years old or older), time since diabetes diagnosis (less than 12 months or between 12 and 36 months) and body mass index (not overweight) and overweight (overweight and obesity grade I, II and III) ${ }^{(22)}$. In addition, the Kruskal-Wallis test was used to compare the scores obtained in the ACS-Response Index subscales and educational levels [primary, secondary, or trade (postsecondary - technical)/university]. A p-value less than or equal to 0.05 was considered statistically significant in all the tests.

\section{Ethical consideration}

The Research Ethics Committee (IRB) approved the proposal in March 2019 (No. 508/2019). All the participants signed free and informed consent forms after receiving clarification about the study's objectives and procedures; participation was voluntary.

\section{Results}

Of the $60(100 \%)$ individuals who participated in the study, predominantly women (65\%). Ages ranged from 27.9 to 89.8 years old, and the mean age was 55 (Standard Deviation - S.D.=11.6). Most participants had completed the secondary level of education. The mean time since participants were diagnosed with type 2 diabetes was 23.2 months. Hypertension was the main comorbidity reported (70\%). The majority of the participants had some level of obesity, and $76.7 \%$ were engaged in some form of exercise activity (Table 1 ).

Table 1 - Sociodemographic and clinical characteristics of the 60 participants. Linden, Guyana, 2020

\begin{tabular}{|c|c|}
\hline Variable & $N(\%)$ \\
\hline \multicolumn{2}{|l|}{ Sex } \\
\hline Female & $39(65)$ \\
\hline Male & $21(35)$ \\
\hline \multicolumn{2}{|c|}{ Age (years) Mean=55; S.D. ${ }^{*}=11.6$} \\
\hline \multicolumn{2}{|l|}{ Educational level } \\
\hline Primary & $25(41.7)$ \\
\hline Secondary & $26(43.3)$ \\
\hline University & $6(10.0)$ \\
\hline Trade School & $3(5.0)$ \\
\hline \multicolumn{2}{|c|}{$\begin{array}{l}\text { Time since diabetes diagnosis (months) Mean=23.2; } \\
\text { S.D. }=9.5\end{array}$} \\
\hline Comorbidities (yes) & $54(90.0)$ \\
\hline Hypertension & $42(70.0)$ \\
\hline Coronary Artery Disease & $4(6.7)$ \\
\hline Neuropathy & $10(16.7)$ \\
\hline Nephropathy & $3(5.0)$ \\
\hline Retinopathy & $20(33.3)$ \\
\hline \multicolumn{2}{|c|}{$\begin{array}{l}\text { Body mass index (yes) Mean= } 31.4 \text {; S.D. }=5.7 \\
\text { eutrophic }\end{array}$} \\
\hline Eutrophic & $6(10.0)$ \\
\hline Overweight & 19 (31.7) \\
\hline Obesity I & $19(31.7)$ \\
\hline Obesity II & $14(23.3)$ \\
\hline Obesity III & $2(3.3)$ \\
\hline Physical activity (yes) & $46(76.7)$ \\
\hline Walking & $38(63.3)$ \\
\hline Running & $4(6.7)$ \\
\hline Riding & $3(5.0)$ \\
\hline
\end{tabular}

${ }^{*}$ S.D. = Standard Deviation 
The number of correct answers provided to each item of the Knowledge subscale and the percentage of correct answers was calculated for each participant (Table 2 ). Only two participants (3.3\%) correctly answered more than $70 \%$ of the questions in the
Knowledge subscale. The total mean score obtained in this subscale was 9.12. Less than half of the participants were able to identify common symptoms of a heart attack, such as chest pain/pressure/tightness (44.1\%), arm pain (45\%), and sweating (30\%).

Table 2 - Descriptive statistics for the Knowledge subscale items - Acute Coronary Syndrome - Response Index (ACSResponse Index). Linden, Guyana, 2020

\begin{tabular}{|c|c|}
\hline ACS*-Response Index Knowledge subscale & $\begin{array}{c}\text { Total mean score (S.D.) } \\
9.12(3.4)\end{array}$ \\
\hline \multirow{2}{*}{ Correct answer for each item } & $\begin{array}{l}\text { Total median score (range) } \\
9.0(4-16)\end{array}$ \\
\hline & $N(\%)$ \\
\hline 1. Lower abdominal pain ${ }^{\ddagger}(\mathrm{N}=59)$ & $43(72.9)$ \\
\hline 2. Arm pain or shoulder pain $(\mathrm{N}=60)$ & $27(45.0)$ \\
\hline 3. Arm paralysis ${ }^{\ddagger}(n=56)$ & $43(76.8)$ \\
\hline 4. Back pain $(\mathrm{N}=58)$ & $25(43.1)$ \\
\hline 5. Chest pain/pressure/tightness $(\mathrm{N}=58)$ & $26(44.1)$ \\
\hline 6. Chest discomfort (heaviness, burning, tenderness) $(\mathrm{N}=60)$ & $23(38.3)$ \\
\hline 7. Cough $^{\ddagger}(\mathrm{N}=56)$ & $40(71.4)$ \\
\hline 8. Dizziness, light headedness $(\mathrm{N}=57)$ & $19(33.3)$ \\
\hline 9. Headache ${ }^{\ddagger}(\mathrm{N}=59)$ & $31(52.5)$ \\
\hline 10. Heartburn/indigestion/stomach problem $(n=60)$ & $29(48.3)$ \\
\hline 11. Jaw pain $(\mathrm{N}=59)$ & $16(27.1)$ \\
\hline 12. Loss of consciousness/fainting $(\mathrm{N}=59)$ & $21(35.6)$ \\
\hline 13. Nausea/vomiting ( $\mathrm{N}=59)$ & $20(33.9)$ \\
\hline 14. Neck pain $(\mathrm{N}=58)$ & $26(44.8)$ \\
\hline 15. Numbness/tingling in arm or hand $d^{\ddagger} \mathrm{N}=60$ & $26(43.3)$ \\
\hline 16. Pale, ashen, loss/change of color $(\mathrm{N}=59)$ & $16(27.1)$ \\
\hline 17. Palpitations/rapid heart rate $(\mathrm{N}=59)$ & $29(49.2)$ \\
\hline 18. Shortness of breath/difficulty breathing $(\mathrm{N}=60)$ & $30(50.0)$ \\
\hline 19. Slurred speech ${ }^{\ddagger}(N=57)$ & $37(64.9)$ \\
\hline 20. Sweating $(\mathrm{N}=60)$ & $18(30.0)$ \\
\hline 21. Weakness/fatigue $(\mathrm{N}=59)$ & $12(20.3)$ \\
\hline
\end{tabular}

${ }^{*}$ ACS = Acute Coronary Syndrome; ${ }^{+}$S.D. = Standard Deviation; ${ }^{\ddagger}$ Reverse code

As shown in Table 3, all the 60 participants answered the five items of the Attitudes subscale concerning ACS. The total mean score was $11.2($ S.D.=3.5). Most of the participants were sure they could get help for themselves $($ mean $=2.8 ;$ S.D. $=0.8)$ and others $($ mean=2.6; S.D. $=0.9)$ if they noticed a heart attack. On the other hand, most of the participants were unsure if they could recognize the signs and symptoms of a heart attack in someone else (mean=1.8; S.D. $=0.9$ ). 
Table 3 - Descriptive statistics for Attitudes subscale items - Acute Coronary Syndrome - Response Index (ACSResponse Index). Linden, Guyana, 2020

\begin{tabular}{|c|c|}
\hline ACS*-Response Index - Attitudes subscale & $\begin{array}{l}\text { Total median score (range) } \\
\qquad 11.5(5-18)\end{array}$ \\
\hline Items & $\begin{array}{l}\text { Total mean score (S.D. })^{\dagger} \\
11.2(3.5)\end{array}$ \\
\hline $\begin{array}{l}\text { 22. How sure are you that you could recognize the signs and symptoms of a heart attack in } \\
\text { someone else? }\end{array}$ & $1.8(0.9)$ \\
\hline $\begin{array}{l}\text { 23. How sure are you that you could recognize the signs and symptoms of a heart attack in } \\
\text { yourself? }\end{array}$ & $2.0(0.9)$ \\
\hline $\begin{array}{l}\text { 24. How sure are you that you could tell the difference between the signs or symptoms of a } \\
\text { heart attack and other medical problems? }\end{array}$ & $2.0(1.0)$ \\
\hline $\begin{array}{l}\text { 25. How sure are you that you could get help for someone if you thought they were having a } \\
\text { heart attack? }\end{array}$ & $2.6(0.9)$ \\
\hline $\begin{array}{l}\text { 26. How sure are you that you could get help for yourself if you thought you were having a } \\
\text { heart attack? }\end{array}$ & $2.8(0.8)$ \\
\hline
\end{tabular}

${ }^{*}$ ACS $=$ Acute Coronary Syndrome $;{ }^{+}$S.D. $=$Standard Deviation

Table 4 shows the results for the Beliefs subscale. The total mean score for this subscale was 21.3 (S.D.=4.5), and the number of patients who answered the items of the Beliefs subscale ranged from 56 to 60 . The item with the highest mean score in this subscale was "I would be embarrassed to go to the hospital if I thought I was having a heart attack, but I wasn't" (mean=3.2, S.D. $=0.9)$. The item that showed the lowest mean score was "If I thought I was having a heart attack, I would go to the hospital right away" (mean=1.7; S.D.=1.0).

Table 4 - Descriptive statistics for Beliefs subscale items - Acute Coronary Syndrome - Response Index (ACS-Response Index). Linden, Guyana, 2020

\begin{tabular}{|c|c|}
\hline ACS*-Response Index - Beliefs subscale & $\begin{array}{l}\text { Total median score (range) } \\
\qquad 22(7-28)\end{array}$ \\
\hline Items & $\begin{array}{l}\text { Total mean score (S.D. })^{\dagger} \\
\qquad 21.3(4.5)\end{array}$ \\
\hline $\begin{array}{l}\text { 27. If I have chest pain that doesn't stop after } 15 \text { minutes, I should get to the hospital as soon as } \\
\text { possible }{ }^{\ddagger}(\mathrm{N}=60)\end{array}$ & $2.1(1.0)$ \\
\hline $\begin{array}{l}\text { 28. I would be embarrassed to go to the hospital if I thought I was having a heart attack, but I } \\
\text { wasn't }(N=59)\end{array}$ & $3.2(0.9)$ \\
\hline $\begin{array}{l}\text { 29. If I thought I was having a heart attack, I would wait until I was very sure before going to the } \\
\text { hospital }(N=59)\end{array}$ & $3.2(0.9)$ \\
\hline $\begin{array}{l}\text { 30. If I thought I was having a heart attack, I would rather have someone drive me to the hospital } \\
\text { than have an ambulance come to my home }(\mathrm{N}=59)\end{array}$ & $2.6(1.0)$ \\
\hline $\begin{array}{l}\text { 31. If I'm having chest pain and I'm not very sure if it's a heart attack, I should go to the hospital }{ }^{\ddagger} \\
(N=58)\end{array}$ & $2.1(0.9)$ \\
\hline $\begin{array}{l}\text { 32. Because of the cost of medical care, I would want to be absolutely sure I was having a heart } \\
\text { attack before going to the hospital }(\mathrm{N}=58)\end{array}$ & $1.8(0.9)$ \\
\hline 33. If I thought I was having a heart attack, I would go to the hospital right away ${ }^{\ddagger}(\mathrm{N}=59)$ & $1.7(1.0)$ \\
\hline
\end{tabular}

${ }^{*}$ ACS $=$ Acute Coronary Syndrome; ${ }^{+}$S.D. = Standard Deviation, ${ }^{*}$ Reverse code

Table 5 shows the results of the subscales of the ACS-Response Index according to sex, age, physical activity, time since the diabetes diagnosis, body mass index, and educational level. Participants diagnosed with type 2 diabetes less than 12 months ago scored higher on the Attitude subscales than those diagnosed from 12 to 36 months $(p=0.049)$. The opposite was found for the Beliefs subscale $(p=0.049)$. The participants 60 years old or older scored significantly higher in the Beliefs subscale $(p=0.001)$ than those younger than 60 years old (Table 5). Statistically significant differences were found when comparing the scores obtained in the Knowledge $(p=0.008)$ and Attitude $(p=0.009)$ subscales according to education level. 
Table 5 - Comparison of Acute Coronary Syndrome - Response Index (ACS-Response Index) subscales according to sex, age, time since diabetes diagnosis, body mass index, and educational level. Linden, Guyana, 2020

\begin{tabular}{|c|c|c|c|c|c|c|}
\hline \multirow{3}{*}{ Variables } & \multicolumn{6}{|c|}{ ACS*-Response Index subscales } \\
\hline & \multicolumn{2}{|c|}{ Knowledge } & \multicolumn{2}{|c|}{ Attitude } & \multicolumn{2}{|l|}{ Beliefs } \\
\hline & Median (Range) & $p$-value & Median (Range) & $p$-value & Median (Range) & $p$-value \\
\hline Sex & & $0.656^{\dagger}$ & & $0.846^{\dagger}$ & & $0.271^{\dagger}$ \\
\hline Female $(n=39)$ & $9.5(4.0-15.0)$ & & $11.0(5.0-18.0)$ & & $22.0(7.028 .0)$ & \\
\hline Male $(\mathrm{n}=21)$ & $8.00(4.0-16.0)$ & & $12.0\left(\begin{array}{l}6.0 \\
16.0\end{array}\right)$ & & $23.0(13.0-28.0)$ & \\
\hline Age (years) & & $0.573^{\dagger}$ & & $0.153^{\dagger}$ & & $0.001^{\dagger}$ \\
\hline$<60(n=41)$ & $8.0(4.0-16.0)$ & & $12.0(5.0-18.0)$ & & $21.0(7.0-28.0)$ & \\
\hline $60+(n=45)$ & $9.0(4.0-14.0)$ & & $9.0(5.0-17.0)$ & & $23.0(15.0-27.0)$ & \\
\hline$P A^{\ddagger}$ & & $0.677^{\dagger}$ & & $0.178^{\dagger}$ & & $0.335^{\dagger}$ \\
\hline Yes $(n=9)$ & $8.0(4.0-16.0)$ & & $11.0(5.0-18.0)$ & & $22.0(7.0-28.0)$ & \\
\hline No $(n=51)$ & $11.0(5.0-12.0)$ & & $8.0(6.0-15.0)$ & & $25.0(13.0-27.0)$ & \\
\hline Time Diag. ${ }^{\S}$ & & $0.138^{\dagger}$ & & $0.049^{\dagger}$ & & $0.049^{\dagger}$ \\
\hline Less than 12 months $(n=27)$ & $10.0(4.0-16.0)$ & & $13.0(5.0-17.0)$ & & $20.0(13.0-28.0)$ & \\
\hline From 12 to 36 months $(n=33)$ & $8.0(4.0-14.0)$ & & $10.0(5.0-18.0)$ & & $23.0(7.0-28.0)$ & \\
\hline BMI" & & $0.646^{\dagger}$ & & $0.405^{\dagger}$ & & $0.968^{\dagger}$ \\
\hline Not overweight $(n=6)$ & $8.0(5.0-1720)$ & & $8.5(6.0-15.0)$ & & $21.5(16.0-27.0)$ & \\
\hline Overweight ( $n=44)$ & $9.0(4.0-16.0)$ & & $12.0(5.0-18.0)$ & & $22.0(7.0-28.0)$ & \\
\hline Educational Level & & $0.008 \pi$ & & $0.009 \pi$ & & $0.109 \pi$ \\
\hline Primary $(n=25)$ & $7.5(4.0-15.0)$ & & $9.0(5.0-17.0)$ & & $23.0(13.0-28.0)$ & \\
\hline Secondary $(n=24)$ & $9.0(4.0-14.0)$ & & $12.0(5.0-18.0)$ & & $22.0(7.0-28.0)$ & \\
\hline Trade or university $(n=9)$ & $13.5(7.0-16.0)$ & & $14.0(11.0-15.0)$ & & $18.0(16.0-27.0)$ & \\
\hline
\end{tabular}

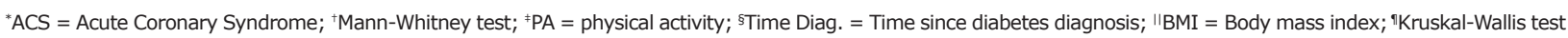

\section{Discussion}

This study's results showed a deficit of knowledge among Guyanese patients with type 2 diabetes regarding ACS symptoms. This study's participants scored lower in the ACS Knowledge subscale than those in other studies $^{(8,17-18)}$. Other authors report a more significant number of participants with more than $70 \%$ of correct answers in the Knowledge subscale ${ }^{(8,15-16)}$ compared to this study's participants; $70 \%$ of correct answers is the cut-off point adopted by other authors to indicate a satisfactory result in this subscale ${ }^{(8,13,15-16)}$. Only two participants (3.3\%) in this study answered more than $70 \%$ of the answers in the Knowledge subscale correctly. The difference in results may be due to the characteristics of the sample. Other studies' participants ${ }^{(8,15-16)}$ may have referred to their experiences considering their diagnoses of coronary heart disease and myocardial infarction, whereas only four persons reported these comorbidities in this study. These results are in line with Leventhal's Model, which states that mental constructions about the disease are formed by a patient's experiences and those of other familiar people ${ }^{(14)}$. Another reason may be related to educational level, considering that $41 \%$ of this study's participants had attended elementary school only, which may impose challenges for health education.

A smaller percentage of this study's participants recognized chest pain as the most typical symptom of this syndrome. In a study conducted in Nepal(17), 60\% of the participants could not identify a single symptom of a heart attack, and only $20 \%$ reported chest pain as a symptom of a heart attack. Other authors $(8,13,15-16,23)$ report that chest pain was the symptom with the highest score. It is important to note that the three items with the highest score in this study are not identified as symptoms of ACS as reported by the literature ${ }^{(9)}$. These results may be related to the profile of this study's participants, i.e., older adults who may often confuse pain in the sternum area with pain in the stomach.

The total mean score obtained in the Attitudes subscale was similar to that obtained by Jordanian patients $^{(16)}$; however, it is lower than that obtained by 
Irish $^{(8)}$ and Lebanese patients ${ }^{(15)}$. In this study, the mean score obtained in the Beliefs subscale was lower than those reported by the studies previously mentioned(8,15-16). The items with the highest average score in the Attitudes subscale ("How sure are you that you could get help for someone if you thought s/he was having a heart attack?" and "How sure are you that you could get help for yourself if you thought you were having a heart attack?") reflect the action of seeking help. However, perception regarding the need to seek help in a heart attack depends on the knowledge of symptoms. In this study, the item that reflects the ability to recognize symptoms obtained the lowest mean score: "How sure are you that you could recognize the signs and symptoms of a heart attack in someone else?" Other authors ${ }^{(8,24)}$ state that a higher number of participants reported they should get to a hospital as soon as possible if they had chest pain that would not stop after 15 minutes. Participants from other studies $^{(15-16)}$ were also more positive about their ability to get help for themselves if they had a heart attack than for others.

The item in the Beliefs subscale that obtained the highest mean score, "I would be embarrassed to go to the hospital if I thought I was having a heart attack, but I wasn't" reflects a lack of knowledge about the risk factors for ACS and its severity. In Guyana, people often resort to hot drinks, such as garlic tea or anise or ginger tea, to burp in an attempt to relieve pain. Seeking the emergency service in the face of a heart attack depends on knowledge about the symptoms and how a patient should respond ${ }^{(15)}$. Sociocultural aspects can also influence the interpretation and responses to $\operatorname{ACS}^{(25)}$. Delay in seeking treatment for acute myocardial infarction contributes to increased mortality.

This study's results revealed that the participants with more knowledge regarding ACS symptoms and the best attitudes to respond to a heart attack also had the highest educational levels. Other studies' findings show that inappropriate knowledge was related to lower educational levels ${ }^{(13,16)}$. One study using the ACS-Response Index to test the effectiveness of an application that uses simulation to interact with users reports that the factor associated with greater knowledge was having a university degree (26).

Several studies ${ }^{(13,27)}$ report that women had more knowledge of cardiovascular diseases than men, though the opposite was found in a study addressing Jordanian patients ${ }^{(16)}$. No significant differences were found in this study between men's and women's knowledge. Similar results were found in an investigation evaluating the knowledge of workers from a Nigerian University regarding heart disease risk factors ${ }^{(28)}$. Additionally, a literature review focusing on the knowledge of symptoms and risk factors for heart disease reports that both women and men had a low level of knowledge about $\operatorname{ACS}^{(11)}$.

In this study, participants 60 years old or older scored significantly higher on the Beliefs scale than their younger counterparts. However, no statistically significant differences were found between these two groups regarding the Knowledge and Attitudes subscales. Other authors report that older adults scored lower in the Knowledge ${ }^{(13)}$ and Attitude subscales ${ }^{(15)}$ than younger patients.

In this study, $76.7 \%$ of the participants reported at least one type of physical activity, mainly walking. However, no significant differences were found in knowledge measures between patients reporting a physical activity and those who did not. The number of overweight participants or with some degree of obesity was high in this study. Obesity is recognized as a public health problem in Guyana(5) and is twice more frequent among women $(36.6 \%)$ than men $(16.0 \%)^{(6)}$.

Georgetown and Linden are the largest cities in Guyana, associated with urbanization and, consequently, with changes in eating habits, levels of physical activity, and the use of alcohol and drugs. For this reason, cardiovascular diseases are on the rise. In addition, these lifestyle changes increase exposure to other cardiovascular risk factors (e.g., diabetes, obesity, and hypertension)(29). Despite public health policies to prevent and care for chronic conditions in Guyana, the widespread belief that chronic non-communicable diseases, like diabetes and cardiovascular diseases, are consequences inherent to the aging process hinders the prevention and management of these diseases ${ }^{(30)}$. This cultural factor may contribute to patients' lack of interest in disease self-management. Essential self-care behavior among people with diabetes depends on the knowledge of specific disease management, relating to healthy eating habits, being physically active, blood sugar monitoring, compliance with medications, and acquiring good problem-solving skills to cope with illness-related problems and other associated conditions.

A study reports that an educational program based on the development of empowerment principles was effective for people with type 2 diabetes $^{(31)}$. Educational strategies empower knowledge, skills, and self-confidence, enabling people with chronic conditions to assume responsibility for managing their diseases ${ }^{(31)}$. Therefore, the education people with diabetes receive should focus not only on expanding their knowledge about the disease but also on cultivating a self-care attitude to prevent cardiovascular problems and decrease the time they take to seek help in cardiac emergencies.

This study's findings show that participants reporting less than 12 months since type 2 diabetes was diagnosed 
obtained statistically significantly higher scores in the Attitudes subscale than those reporting between 12 and 36 months. Future studies should address this aspect, considering that the second group also scored lower in the Beliefs subscale, and diabetes is a significant risk factor for the development of coronary artery disease ${ }^{(2)}$.

One of this study's limitations refers to its small sample size. However, the characteristics of the participants are representative of the Guyanese population served by the public hospitals, and the results of this study need to be explored considering the population's cultural and economic factors that affect disease management. Another limitation concerns missing data in medical records so that some comorbidities could not be confirmed.

Nonetheless, these findings contribute to educational programs focused on improving knowledge, attitudes, and beliefs on ACS among populations from other regions, such as South America and the Caribbean. In addition, these results call the attention of health professionals and policymakers to the challenges of improving health education among patients with type 2 diabetes concerning ACS symptoms and how to respond to a heart attack.

Further studies adopting more diverse samples and including patients living in rural areas are needed. In addition, it is important to investigate the types of education provided by health care professionals to type 2 diabetes patients at all levels of health care services in Guyana, including hospitals and small services in rural areas. In addition to preventing cardiovascular disease and improving the approach to type 2 diabetes selfmanagement, educational programs can decrease delays in seeking assistance in case of a heart attack.

Patients with type 2 diabetes receiving timely and proper education provided by nurses, doctors, and other healthcare workers become familiar with the signs and symptoms of the different complications, including those concerning ACS, and have better attitudes towards the need to seek help and the importance of self-management.

\section{Conclusion}

This study's findings revealed that Guyanese patients with type 2 diabetes lack knowledge regarding ACS symptoms and how to respond (Attitudes) to a heart attack appropriately, i.e., they are uncertain about the appropriate actions to take for themselves and others.

Patients with the highest educational levels (trade or university degree) obtained the highest scores on the Knowledge and Attitude subscales. Participants diagnosed with type 2 diabetes less than 12 months ago scored higher on the Attitude subscales than those diagnosed between 12 and 36 months; this group also obtained the lowest scores on the Beliefs subscale. Participants 60 years old or older scored higher on the Beliefs subscale than their younger counterparts.

These findings highlight the need for the multidisciplinary healthcare team to initiate health education at the time of the clinical diagnosis to motivate patients with type 2 diabetes to cultivate positive attitudes toward self-management and help-seeking behavior.

\section{References}

1. World Health Organization. Noncommunicable diseases country profiles 2018. [Internet]. Geneva: WHO; 2018 [cited 2019 Jul 10]. Available from: https://www.who. int/nmh/publications/ncd-profiles-2018/en/

2. Naito R, Miyauchi K. Coronary Artery Disease and Type 2 Diabetes Mellitus. Int Heart J. 2017;58(4):475-80. doi: http://doi.org/10.1536/ihj.17-191

3. Cho NH, Shaw JE, Karuranga S, Huang Y, Rocha Fernandes JD, Ohlrogge AW, et al. IDF Diabetes Atlas: Global estimates of diabetes prevalence for 2017 and projections for 2045. Diabetes Res Clin Pract. 2018;138:271-81. doi: http://doi.org/10.1016/j. diabres.2018.02.023

4. Razzaghi H, Martin DN, Quesnel-Crooks S, Hong Y, Gregg E, Andall-Brereton G, et al. 10-year trends in noncommunicable disease mortality in the Caribbean region. Rev Panam Salud Publica. 2019;43:e37. doi: http://doi.org/10.26633/RPSP.2019.37

5. Gampat R. Guyana: Leading causes of death during the Last 120 years. [Internet]. 2019 Apr. [cited 2020 Apr 10]. Available from: https://papers.ssrn.com/sol3/papers. cfm?abstract_id=3399003

6. Ke C, Persaud S, Singh K, Ostrow B, Lebovic G, Hincapié $C$, et al. Interaction between sex and rurality on the prevalence of diabetes in Guyana: a nationally representative study. BMJ Open Diabetes Res Care. 2020;8(1):e001349. doi: http://doi.org/10.1136/ bmjdrc-2020-001349

7. Sato C, Wakabayashi K, Ikeda N, Honda Y, Sato K, Suzuki $T$, et al. Influence of sex on the incidence of potential coronary artery disease and long-term outcomes in asymptomatic patients with diabetes mellitus. Int J Cardiol Heart Vasc. 2020 Mar 26;27:100504. doi: http:// doi.org/10.1016/j.ijcha.2020.100504

8. O'Brien F, O'Donnell S, McKee G, Mooney M, Moser D. Knowledge, attitudes, and beliefs about acute coronary syndrome in patients diagnosed with ACS: an Irish crosssectional study. Eur J Cardiovasc Nurs. 2013;12(2):201-8. doi: http://doi.org/10.1177/1474515112446544

9. Riegel B, McKinley S, Moser DK, Meischke H, Doering L, Dracup K. Psychometric evaluation of the Acute Coronary Syndrome (ACS) Response Index. Res Nurs 
Health. 2007;30(6):584-94. doi: http://doi.org/10.1002/ nur. 20213

10. Al Khayyal HA, El Geneidy M, El Shazly SAM. Elders' Knowledge about risk factors of coronary heart disease, their perceived risk, and adopted preventive behaviors. JEP. [Internet]. 2016 [cited 2019 Jul 10];7(10);8998. Available from https://files.eric.ed.gov/fulltext/ EJ1099545.pdf

11. Jensen LA, Moser DK. Gender differences in knowledge, attitudes, and beliefs about heart disease. Nurs Clin North Am. 2008;43(1):77-104; vi-vii. doi: http://doi.org/10.1016/j.cnur.2007.10.005

12. Garrido D, Petrova D, Catena A, Ramírez-Hernández JA, Garcia-Retamero R. Recognizing a Heart Attack: Patients' Knowledge of Cardiovascular Risk Factors and Its Relation to Prehospital Decision Delay in Acute Coronary Syndrome. Front Psychol. 2020 Aug 25;11:2056. doi: http://doi.org/10.3389/fpsyg.2020.02056

13. Dracup K, McKinley S, Doering LV, Riegel B, Meischke $\mathrm{H}$, Moser DK, et al. Acute coronary syndrome: what do patients know? Arch Intern Med. 2008;168(10):1049-54. doi: http://doi.org/10.1001/archinte.168.10.1049

14. Hagger MS, Orbell S. The common sense model of illness self-regulation: a conceptual review and proposed extended model. Health Psychol Rev. 2021 Feb 1:1-31. doi: http://doi.org/10.1080/17437199.2021.1878050

15. Noureddine S, Dumit NY, Maatouk H. Patients' knowledge and attitudes about myocardial infarction. Nurs Health Sci. 2020;22(1):49-56. doi: http://doi. org/10.1111/nhs. 12642

16. Alfasfos N, Darawad MW, Nofal B, Samarkandi AO, Abdulqader B. Knowledge, attitudes, beliefs and perceived risk of acute coronary syndrome among Jordanian patients. Health. 2016;8(15):1830-44. doi: http://doi. org/10.4236/health.2016.815175

17. Vaidya A, Aryal UR, Krettek A. Cardiovascular health knowledge, attitude and practice/behaviour in an urbanising community of Nepal: a populationbased cross-sectional study from Jhaukhel-Duwakot Health Demographic Surveillance Site. BMJ Open. 2013;3(10):e002976. doi: http://doi.org/10.1136/ bmjopen-2013-002976

18. Elnaem MH, Elrggal ME, Syed N, Naqvi AA, Hadi MA. Knowledge and perceptions towards cardiovascular disease prevention among patients with type 2 diabetes mellitus: a review of current assessments and recommendations. Curr Diabetes Rev. 2021;17(4):503-11. doi: http://doi. org/10.2174/1573399816666200914140939

19. Liu $X L$, Willis $K$, Fulbrook $P, W u ~ C J$, Shi $Y$, Johnson $M$. Factors influencing self-management priority setting and decision-making among Chinese patients with acute coronary syndrome and type 2 diabetes mellitus. Eur J
Cardiovasc Nurs. 2019 Dec;18(8):700-10. doi: http:// doi.org/10.1177/1474515119863178

20. Adam L, O'Connor C, Garcia AC. Evaluating the Impact of Diabetes Self-Management Education Methods on Knowledge, Attitudes and Behaviours of Adult Patients With Type 2 Diabetes Mellitus. Can J Diabetes. 2018 Oct;42(5):470-477.e2. doi: http://doi.org/10.1016/j. jcjd.2017.11.003

21. Fayers PM, Machin D. Quality of Life. The assessment, analysis and reporting of patient-reported outcomes. $3^{\text {rd }}$ ed. London: John Wiley \& Sons; 2016. p. 89-124.

22. Sommer I, Teufer B, Szelag M, NussbaumerStreit B, Titscher V, Klerings I, et al. The performance of anthropometric tools to determine obesity: a systematic review and meta-analysis. Sci Rep. 2020 Jul 29;10(1):12699. doi: http://doi.org/10.1038/s41598020-69498-7

23. Albarqouni $L$, Smenes $K$, Meinertz $T$, Schunkert $H$, Fang $X$, Ronel J, et al. Patients' knowledge about symptoms and adequate behaviour during acute myocardial infarction and its impact on delay time: Findings from the multicentre MEDEA Study. Patient Educ Couns. 2016;99(11):1845-51. doi: http://doi.org/10.1016/j.pec.2016.06.007

24. Cao X, Cao Y, Salamonson Y, Digiacomo M, Chen Y, Chang $S$, et al. Translation and validation of the Chinese version of the Acute Coronary Syndrome Response Index (C-ACSRI). Int J Nurs Stud. 2012;49(10):1277-90. doi: http://doi.org/10.1016/j.ijnurstu.2012.04.008

25. Osokpo O, Riegel B. Cultural factors influencing selfcare by persons with cardiovascular disease: an integrative review. Int J Nurs Stud. 2019;9:103383. doi: http://doi. org/10.1016/j.ijnurstu.2019.06.014

26. Tongpeth J, Du H, Barry T, Clark RA. Effectiveness of an Avatar application for teaching heart attack recognition and response: A pragmatic randomized control trial. J Adv Nurs. 2020;76(1):297-311. doi: http://doi.org/10.1111/ jan. 14210

27. Andsoy II, Tastan S, Iyigun E, Kopp LR. Knowledge and attitudes towards cardiovascular disease in a population of North Western Turkey: a crosssectional survey. IJCS. [Internet]. 2015;8(1):11524. [cited 2019 Jul 10]. Available from http://www. internationaljournalofcaringsciences.org/docs/14-OriginalAndsoy.pdf

28. Akintunde AA, Akintunde T, Opadijo OG. Knowledge of heart disease risk factors among workers in a Nigerian University: A call for concern. Niger Med J. 2015;56(2):915. doi: http://doi.org/10.4103/0300-1652.150688 29. Sockalingam L, Desai D, Wong A, Azim G, Doobay $B$, Khalid $Z$, et al. The rise in cardiovascular risk factors and chronic diseases in Guyana: a narrative review. Ann Glob Health. 2021 May 31;87(1):46. doi: http://doi. org/10.5334/aogh.3060 
30. Pan American Health Organization/World Health Organization. Guyana country cooperation strategy 2016-2020. Strengthening health systems to achieve universal health. [Internet]. Georgetown: PAHO/WHO Representative in Guyana; 2018 [cited 2021 July 18]. Available from: https://www.paho.org/guy

31. Santos JCD, Cortez DN, Macedo MML, Reis EA, Reis IA, Torres HC. Comparison of education group strategies and home visits in type 2 diabetes mellitus: clinical trial. Rev. Latino-Am. Enfermagem. 2017;25:e2979. doi: http://doi. org/10.1590/1518-8345.2315.2979

\section{Authors' contribution:}

Study concept and design: Camille Alardis Hunte Johnson, Lídia Aparecida Rossi. Obtaining data: Camille Alardis Hunte Johnson. Data analysis and interpretation: Camille Alardis Hunte Johnson, Natássia Condilo Pitta, Carina Aparecida Marosti Dessotte, Rosana Aparecida Spadoti Dantas, Lídia Aparecida Rossi. Statistical analysis: Natássia Condilo Pitta, Carina Aparecida Marosti Dessotte, Rosana Aparecida Spadoti Dantas. Obtaining financing: Camille Alardis Hunte Johnson. Drafting the manuscript: Camille Alardis Hunte Johnson, Natássia Condilo Pitta, Carina Aparecida Marosti Dessotte, Rosana Aparecida Spadoti Dantas, Lídia Aparecida Rossi. Critical review of the manuscript as to its relevant intellectual content: Camille Alardis Hunte Johnson, Natássia Condilo Pitta, Carina Aparecida Marosti Dessotte, Rosana Aparecida Spadoti Dantas, Lídia Aparecida Rossi.

All authors approved the final version of the text.

Conflict of interest: the authors have declared that there is no conflict of interest.

Corresponding author:

Lídia Aparecida Rossi

E-mail: rizzardo@eerp.usp.br

(iD) https://orcid.org/0000-0002-4141-861X
Received: May 11 2021 Accepted: Aug 22 2021

Associate Editor:

Maria Lúcia Zanett

Copyright $($ C 2021 Revista Latino-Americana de Enfermagem This is an Open Access article distributed under the terms of the Creative Commons (CC BY).

This license lets others distribute, remix, tweak, and build upon your work, even commercially, as long as they credit you for the original creation. This is the most accommodating of licenses offered. Recommended for maximum dissemination and use of licensed materials. 